\title{
Organizational Ethical Climate Review
}

\author{
LIU Bing, YUAN Yu-qing \\ Management School, Shandong University, Jinan 250100, China
}

\begin{abstract}
Organizational ethical climate is members' consistent cognition on the ethical environment characteristics. As an important factor in the organizational environment, it draws more and more domestic and foreign scholars' attention. On the basis of the literature, this paper makes integrated analysis on the connotation and types of organizational ethical climate, summing up the organizational ethical climate empirical research framework, listing future research directions and offering suggestions for the domestic research in order to benefit subsequent systematic research.

Index Terms - Organizational Environment, Organizational Climate, Ethical Behavior, Organizational Ethical Climate, Review
\end{abstract}

\section{Introduction}

Organization consists of human capital, organizational systems and social capital elements, existing in the social environment and is always affected by the social environment. The organization's social responsibility requires organizations to improve efficiency and effectiveness, but attention also must be paid to the impact of their actions on society. Ethical issues in the organization have grown to become the organization's focus of attention along with relay capital, technology and system. Western academic study of organizational ethical behavior is accompanied by the rise of business ethics. Organizational ethical environment has an important impact on the ethical decision-making process of the organization, and organizational ethical climate is one of the important variables in organizational ethical environment.

Organizational climate has been an object of psychological research. Researchers believe it can effectively explain the attitudes and behaviors of members in the organization to understand and predict individual and organizational performance. As an organizational climate, organizational ethical climate is conducive not only to shape and improve ethical behavior of employees, increase employee job satisfaction and organizational commitment, but also improve organizational performance, thus promoting the sustainable development of the organization. As one of the effective ways to solve the problem of organizational ethical, ethical climate of the organization increases attention of theoretical and practical area in recent years. Since Murphy and Victor put forward the concept of organizational ethical climate in 1980s', researches on organizational climate have made a series of important achievements, scholars have gradually explored the meaning of organizational ethical climate, classification, structure, and the development of relevant scales. Empirical studies have gained progress, and the former researches not only measured organizational ethical climate's antecedent and outcome variables, but explored the influence of organizational ethical climate intermediary mechanisms and situational factors (such as Alicia SM Leung,2008; Ayse Begun Otken,etc.,2012; Tu
Yulong,2013). In order to keep up with cutting-edge theory, this paper intends to analyze the relevant literature of organizational ethical climate, discuss the meaning of organizational ethical climate, classification, measurement methods, and on the basis of this, combine a framework for organizational ethical climate according to empirical studies. Finally future research directions are suggested for the follow-up studies to benefit researches in this area.

\section{Organizational Ethical Climate}

The concept of organizational climate and organizational ethical climate has a close relationship, according to Parker and Patterson's point of view. Organizational climate is organization's characteristics of a relatively stable internal environment which distinguish from other organizations, similar to the organization's "personality" and is the members' overall cognition on the organization's objective characteristics, while organizational ethical climate is deepening organizational climate.

The concept of organizational ethical climate was first proposed by Murphy et al in 1981. They thought the organization ethical climate is an important factor affecting their ethical behavior, and found that if the organization 's ethical climate changes, ethical behavior will change marketing staff. Victor, who conducted the organizational ethical climate groundbreaking research in 1987, believed that if the concept of ethical is used into organizational management practices, organizational ethical climate would contribute to the formation. According to the basic theory of normative ethical and moral theory and the theory structure of nine climate types proposed by Kohlberg, They conducted 12 studies on the theoretical structure of the organization to verify ethical climate, and then developed the organizational ethical climate questionnaire (ECQ).

Malloy believes that organization ethical climate is organizational members' psychological perception structure of what is in line with ethical behavior, and it makes employees understand the organization's shared values and goals, as well as in the context of the values and goals, what is ethical behavior and what behavior is not allowed, how the ethical problems should be dealt with and resolved, such as who should be responsible for the common cognitive problems.

Summing up above findings, the meaning of organizational ethical climate defined by researchers has much similarity. We believe that the organizational ethical climate is an important organizational climate dimension, which refers to the internal members of the organization for what is ethical behavior, common experience and understanding of how to resolve ethical dilemmas or 
problems. This Cognition will affect individual's attitude to ethical issues, beliefs, motivations and behavioral tendencies, and ultimately affect the ethical behavior of employees and the entire organization.

\section{Types of Organizational Ethical Climate}

On the basis of normative ethical basic theory and Kohlberg's stages of moral development theory, Cullen and Victor (1989) proposed two dimensions of organizational ethical climate: ethical criteria and levels of analysis. In theory, organizational ethical climate can have nine types. In ethical standards, they referred to Kohlberg's (1981) stage theory of individual development of moral, proposing three ethical standards: self-interest, caring and principles, which developed three important ethics: egoism, utilitarianism and deontology (Figure1). The pursuit of self-interest tends to maximize self-gain, and the utilitarianism is seeking to maximize common interests, and deontology emphasizes personal principles or professional standards, specific organizational ethical climate matches the specific ethical standards.

\section{Empirical Study in Abroad}

As an important component of organizational culture, Organizational ethical climate plays an increasingly important role in organizational performance and guiding members' behavior. Scholars mostly adopted Cullen and Victor's theoretical construct of organizational ethical climate to conduct further studies of organizational ethical climate, including organizational ethical climate influence factors and its relationships with other variables.

Kelley and Dorsch (1991) conducted an empirical study on the relationship between ethical climate and organizational identification, using Cullen and Victor's ethical climate questionnaire, and they came to identify that employees' organizational identification and their attitudes to caring ethical climate, instrumental ethical climate were closely related.

Upchurch and Ruhland (1995 and 1996) studied the relationship between ethical climate and leadership, and their results showed that benevolent criteria was more prevalent than principled, and ethical concerns on organizational level was much more than social level.

Deshpande(1996a) studied the relationship between ethical climate, ethical behavior and success, and the results showed that in the caring ethical climate, success and ethical behavior was positively correlate; In the instrumental ethical climate, success was negatively correlated with unethical behavior. Deshpande (1996b) studied the relationship between ethical climate and job satisfaction. He found that certain ethical climate impacted on job satisfaction, but not all ethical climate was influential on job satisfaction.

Wimbush and Shepard (1994) investigated the relationship between ethical climate and personal ethical behavior. They summed up which ethical climate promoted moral behavior of employees; which ethical climate promoted the performance of whole company; and described the leaders playing an important role of in establishing and promoting ethical climate which was conducive to subordinates' ethical behavior.

Steve Bourne and John D. Snead (1999) conducted a study from the perspective of team ethical climate, researching organizational ethical climate's antecedent variables to explore the impact of organizational rules and values on ethical climate. The study also found that as microculture, regional-organizations played moderating role in organization shaping the ethical climate process.

William A. Weeks (2006) conducted a cross-cultural (United States and Mexico) empirical research of the organizational ethical climate on salesperson performance. He found that in United States, organization ethical climate had a relationship between personal organizational commitment and salesperson performance, while there was a negative correlation in ethical development and perception of organizational ethical climate, and organizational ethical climate had no significant relationship with organizational commitment in Mexico.

Craig V. VanSandt, Jon M. Shepard and Stephen M. Zappe (2006) studied the relationship between organizational ethical climate and ethical perception, and showed that the ethical climate altruistic and principled ethical climate were associated with high-level ethical perception, while selfinterest ethical standards and low-level ethical perception were related, and explored the role of individual characteristics.

Alicia S.M. Leung (2008) conducted organizational citizenship behavior (in-role behavior and extra-role behavior) as outcome variable to research ethical climate's impact making employee loyalty as mediator. The results suggested that lower levels of ethical climate (instrumentality and independence) were associated with negative extra-role behavior. In contrast, higher levels of ethical climate (caring and law-and-code) were associated with positive extra-role behavior. Moreover, normative commitment mediated a positive relationship between caring and identification with the company, whereas attitudinal loyalty mediated the negative relationship between independence and altruism.

Meral Elci and Lutfihak Alpkan (2009) conducted an empirical study on organizational ethical climate and job satisfaction, and found that the effects of ethical climatic factors on employee work satisfaction, self-interest climate type appears to negatively influence work satisfaction, whereas team interest, social responsibility and law and professional codes climate types were found to have positive impacts.

DeConinck, James B (2011) studied the organizational ethical climate influence on sales staff's organizational identity, supervisor's trust and turnover intention. The study found organizational ethical climate had a direct impact on supervisor's trust and organizational identification, and independent oriented (personal ethical) had a direct impact on employee turnover, while studies also showed that ethical climate had directly effect on employees' work attitudes and performance. 
Kang, Dae-seok, Stewart, Jim, Kim, Hayeon (2011) studied the perceived external prestige (PEP), organizational ethical climate, leader-member exchange (LMX)'s impact on employee commitment and work attitudes. The study found that organizational ethical climate and leader-member exchange had significant correlation with organizational and professional commitment, and the perceived external prestige only affected organizational commitment; as mediating variables, these two kinds of commitment were influential to staff training motivation and turnover intention .

Anke Arnaud, Marshall Schminke (2012) investigated organizational ethical climate and context of organizations, and proposed that organizational ethical climate influence the context of organizations, thus influencing organizational ethical sentiment and moral sensitivity, thereby affecting the organization's ethical behavior, and through empirical study this conclusion was verified.

Ayse Begun Otken, Tuna Cenkci (2012) explored the impact of paternalistic leadership on organizational ethical climate, taking trust as a moderator, and they found that paternalistic leadership had some effect on ethical climate, partial support was found for the moderating effect of trust in leader on the relationship between PL and ethical climate. theyalso stressed the importance of paternalistic leadership in compliance with the enterprise system processes and responsibility aspects.

Borhani F, Jalali T, Abbaszadeh A, Haghdoost A (2013) conducted a research to determine the correlation between nurses' perception of ethical climate and organizational commitment, and the result indicated a positive correlation among professionalism, caring, rules, independence climate, and organizational commitment. This finding also provided guidance to reduce nurse turnover rate, improve organizational commitment.

Vardaman, James M., Gondo, Maria B., Allen, David G. (2014) studied the organizational ethical climate and employee pro-social rules breaking (PSRB) relationship, and offered a set of propositions that provided theory on the role of each climate type on PSRB to clarify it as an ethical decision, and found that self-interest type were proposed as antecedents to PSRB.

Based on the above empirical researches combed and combining the theory of ethical climate literature review and development proposed by Kelly D. Martin and John B. Cullen $(2006)^{[30]}$, we build a theoretical model of organizational ethical climate as follows(Figure1):

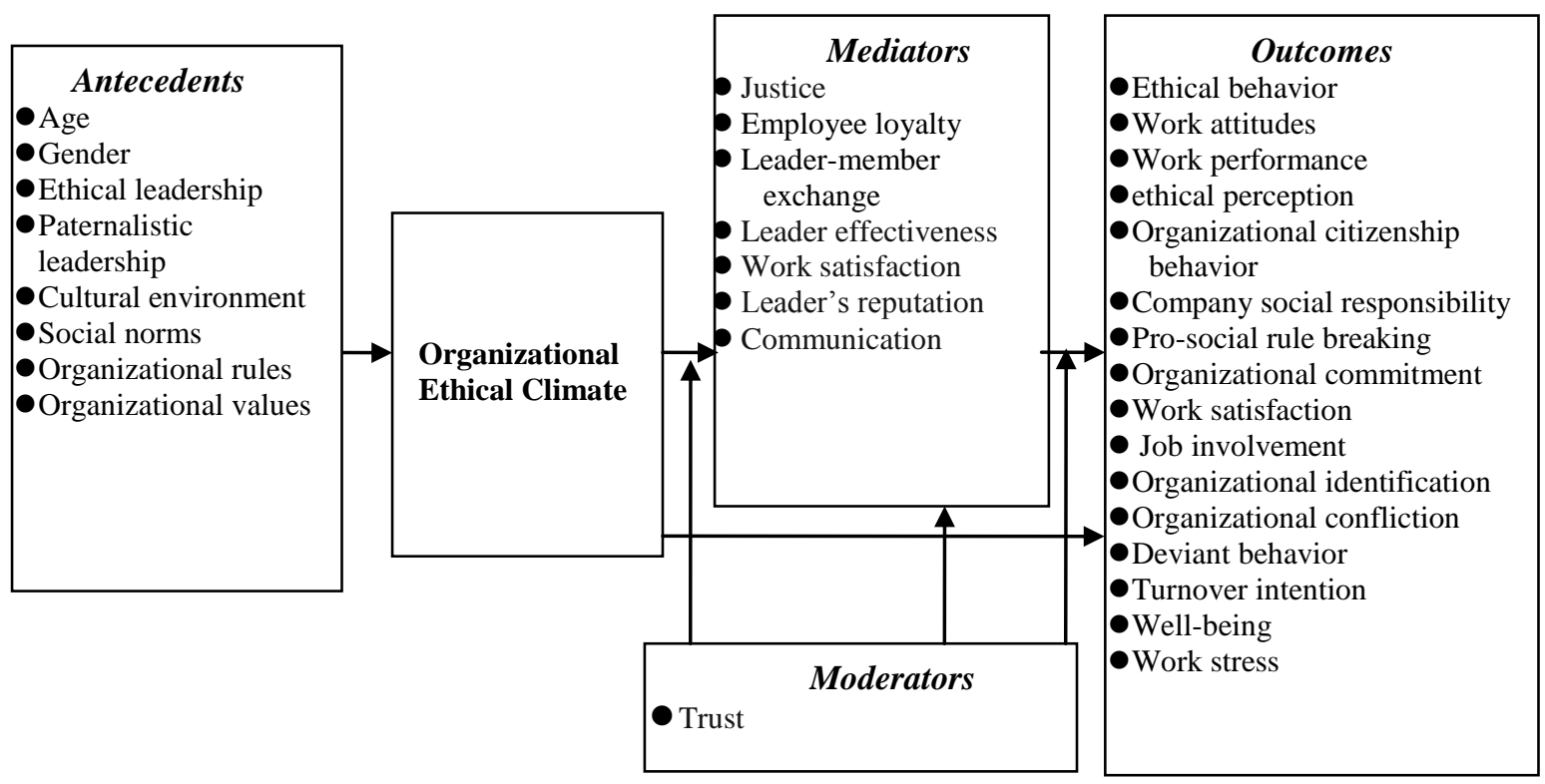

Figure 4. theoretical model of organizational ethical climate

\section{Summary}

Overall, it is necessary to explore the formation of multicultural backgrounds Organizational Ethical Climate, mechanism of action and its effects, research organizations ethical climate of different cultural backgrounds and learn whether there is a constructive conclusion.

\section{Acknowledgement}

This research was financially supported by Shandong University Innovation Foundation 'the relationship between
Chinese company's team ethical climate and team performance' (2012TS192).

\section{References}

[1] Agarwal J, Malloy D C. Ethical work climate dimensions in a nonprofitorganization: an empirical study. Journal of Business Ethics, 1999, 20:1-14.

[2] Anke Arnaud, Marshall Schminke. The Ethical Climate and Context of Organizations: A Comprehensive Model. Organization Science, 2012, 23(6):1767-1780.

[3] Ayse Begun Otken, Tuna Cenkci. The impact of Paternalistic Leadership on Ethical Climate: The Moderating Role of Trust in Leader. Journal of Business Ethics, 2012, 108(4):525-536. 
[4] Borhani F, Jalali T, Abbaszadeh A, Haghdoost A. Nurses' perception of ethical climate and organizational commitment. Nursing Ethics, 2013.

[5] Craig V. VanSandt, Jon M. Shepard, Stephen M. Zappe. An Examination of the Relationship between Ethical Work Climate and Moral Awareness. Journal of Business Ethics, 2006, 68:409-432.

[6] DeConinck, James B. The effects of ethical climate on organizational identification, supervisory trust, and turnover among salespeople. Journal of Business Research, 2011, 64:617-624.

[7] Deshpande S.P. The Impact of Ethical Climate types on Facets of Job Satisfaction: An Emirical Investigation. Journal of Business Ethics, 1996, 15: 600-655.

[8] Kang, Dae-seok, Stewart, Jim, Kim, Hayeon. The effects of perceived external prestige, ethical organizational climate, and leader-member exchange (LMX) quality in employees' commitments and their subsequent attitudes. Personnel Review, 2011, 40:761-784.

[9] Kelly D. Martin, John B. Cullen. Continuities and Extensions of Ethical Climate Theory: A Meta-Analytic Review. Journal of Business Ethics, 2006, 69:175-194.

[10] Kelly S. W., M. J. Dorsch. Ethical Climate, Organizational Commitment, and Indebtedness Among Purchasing Executives. Journal of Personal Selling \& Sales Management, 1991, 11:55-66.

[11] Malloy D C, Agarwal J. Ethical climate in nonprofit organizations: propositions and implications. Nonprofit Management \& Leadership, 2002, 12(1):39-54.

[12] Matching Ethical Work Climate to In-role and Extra-role Behaviors in a Collectivist Work Setting. Journal of Business Ethics, 2008, 79:43-55.

[13] Meral Elci, Lutfihak Alpkan. The Impact of Perceived Organizational Ethical Climate on Work Satisfaction. Journal of Business Ethics, 2009, 84:297-311.
[14] Patterson M G, Warr P, West M. Organizational climate and company productivity: the role of employee affect and employee level. Journal of Occupational and Organizational Psychology, 2004, 77:193-216.

[15] Parker C P, Baltes B B, Young S A, Huff J W, Altmann R A, Lacost H A, Roberts J E. Relationships between psychological climate perceptions and work outcomes: ameta-analytic review. Journal of Organizational Behavior, 2003, 24:389-416.

[16] Steve Bourne, John D. Snead. Environmental Determinants of Organizational Ethical Climate: A Community Perspective. Journal of Business Ethics, 1999, 21: 283-290.

[17] Vardaman, James M., Gondo, Maria B., Allen, David G..Ethical climate and pro-social rule breaking in the workplace. Human Resource Management Review, 2014, 24:108-118.

[18] Victor B, Cullen J B. A theory and measure of ethical climate in organizations. Research in Corporate Social Performance and Policy, 1987, 9:51-71.

[19] Victor B, Cullen J B. A theory and measure of ethical climate in organizations, in W C Frederick, L E Preston (Eds). Business ethics research issues and empirical studied, 1990:77-97.

[20] William A.Weeks, Terry W.Loe, Lawrence B.Chonko, Carlos Ruy Martinez, Kirk Wakefield. Cognitive moral development and the impact of perceived organizational ethical climate on the search for sales force excellence: A cross-cultural study. Journal of Personal Selling \& Sales Management, 2006, XXVI: 205-217.

[21] Wimbush. J. C., Shepard. J. M., Markham. S.E. An Empirical Examination of the Multi-mensionality of Ethical Climate in Organizations. Journal of Business Ethics, 1997, 16:67-77. 